\title{
A Stopped Flow System with Hydrodynamic Injection for Red Blood Cells Osmotic Fragility Test: Possibility for Automatic Screening of Beta-thalassemia Trait
}

\author{
Supada Khonyoung, ${ }^{*}$ Supaporn KRAdTAP HARTWELl, ${ }^{* \dagger}$ Jaroon JaKMUNEE,* \\ Somchai LAPANANTNOPPAKHUN,* Torpong SANGUANSERMSRI,** and Kate GrUdPAN* \\ *Department of Chemistry and Center for Innovation in Chemistry, Faculty of Science, Chiang Mai University, \\ Chiang Mai 50200, Thailand \\ **Department of Pediatrics, Faculty of Medicine, Chiang Mai University, Chiang Mai 50200, Thailand
}

\begin{abstract}
Simple instrumentation and procedure with stopped flow system coupled to hydrodynamic injection and spectrophotometric detection were developed for automatic osmotic fragility test (OFT). OFT is a test for abnormal red blood cells based on the kinetics of their rupturing in a hypotonic saline solution. A portion of red cells was merged on-line with a hypotonic saline solution. They were mixed while flowing into the detector and were stopped for a short period for continuously monitoring the change of turbidity based on a transmission signal. In this work, a possible application of the system for screening of beta-thalassemia trait is demonstrated. Descriptions of instrumentation development and parameter optimization are presented. The system offers advantages over the conventional batch-wise OFT in terms of automation, precision, analysis time and sample volume.
\end{abstract}

(Received December 18, 2008; Accepted January 19, 2009; Published June 10, 2009)

\section{Introduction}

An osmotic fragility test (OFT) is a test of the ability of red blood cells to withstand hemolysis in hypotonic saline solution. The normal, relatively impermeable, biconcave disc-like red cells can maintain osmotic equilibrium with the in-vivo surrounding medium. When cells are placed in a hypotonic saline medium, fluid will move into these cells by osmosis and cause them to rupture. The change in osmotic fragility (OF) has been observed in various situations where the surface-to-volume ratio or membrane physiology of the red cells is altered. ${ }^{1-3}$ Elevated OF (less resistant to hemolysis) has been reported to relate directly to hereditary spherocytosis due to less pressure tolerance of the spherical red cells. ${ }^{4}$ Decrease in OF (more resistant to hemolysis) has been observed in thalassemia, iron deficiency, some forms of liver diseases and lead poisoning. ${ }^{1,5,6}$ In cold-blooded animals such as fish, apart from the salinity of the water they are living in, the temperature and the sexual activity in different seasons also affect the OF of their red cells. ${ }^{7}$ OFT is therefore used for screening of some red blood cell-related diseases in human and pets (such as dogs and cats) and for the environmental and ecological studies of marine animals.

In developing countries with high rates of thalassemia, where budget, facilities and number of trained personnel are limited, prevention of thalassemia is very important and it is necessary that the prevention plan and management be based on economic suitability. Various screening techniques such as OFT, dichlorophenol indophenol precipitation (DCIP) and acid staining

† To whom correspondence should be addressed.

E-mail:kradtas@yahoo.com have been used as alternative cost-effective thalassemia screening methods to cut down on the number of samples that would be needed for a higher-cost analysis such as high performance liquid chromatography (HPLC), polymerase chain reaction (PCR) or DNA study. ${ }^{5,8-11}$

Among many thalassemia screening techniques, OFT is recognized as an effective screening technique for thalassemia triats commonly found in Thailand and in neighbouring countries; i.e. beta-thalassemia trait and alpha-thalassemia- $1,{ }^{10-13}$ especially when the technique is performed in combination with PCR. ${ }^{11,12}$ Even though thalassemia patients have some red cells that are more fragile than normal, a larger portion is less fragile. ${ }^{1}$ This may be due to the presence of some difficult-to-break cells, irregularly shaped cells, and abnormal cell membrane. However, OFT may not be an effective screening technique in the areas where iron deficiency is prevalent, such as in Egypt. ${ }^{14}$ In spite of other body conditions that may cause false positive or false negative results, OFT has been proven by many researchers to be adequately sensitive $(94-98 \%)$ and specific $(70-86 \%)$ for identification of beta-thalassemia, in particular. ${ }^{8-10}$

The common procedure for OFT of human red cells may be found in routine assay as follows: $20 \mu \mathrm{l}$ packed red cells is mixed with $2-4 \mathrm{ml}$ buffer saline solution in a test tube. ${ }^{8,9}$ Various saline concentrations $(0.34,0.36$ and $0.45 \%)$ were reported effective by different groups..$^{8-10,15}$ Results are observed within 30 min. Normal red cells will break and yield clear red solution. Red cells that can tolerate osmotic pressure longer will cause the solution to stay turbid. Normally, a piece of printed paper is placed behind the test tubes to compare the clearness or turbidity of solution by sight; this is known as the naked eyes single-tube red cell osmotic fragility test (NESTROFT) ${ }^{5,8}$ This simple OFT, however, still has points to be considered for improvement 
including precision, accuracy, analysis time and sample volume. Observation of results by bare eyes is prone to human errors, especially in those cases at the border line of positive and negative results. Batch-wise optical detection, known as kinetic one-tube OFT has shown much improved performances with very rare false negatives. ${ }^{10}$ However, some steps such as manual mixing and placing a cuvette in a spectrometer may still cause imprecision. Therefore, an automatic system for kinetic OFT with higher accuracy and precision, one that is rapid and consumes relatively little amount of blood samples, should be beneficial.

Flow injection (FI) is a well-established analytical technique where sample and reagent are mixed in a small piece of tubing while they are flowing to a detector for continuous monitoring. Reaction time and detection time can be fixed by maintaining a constant flow rate. Therefore, detection can be done before the reaction reaches equilibrium and this helps to shorten the analysis time. For the study of a slow kinetic reaction, the flow of solution may be stopped to maximize the reaction progress for better sensitivity. This system is known as stopped flow injection. Such a system is suitable for online kinetic studies of various chemical reactions ${ }^{16-19}$ and should be adaptable for kinetic study of red cells' rupture in OFT.

\section{Experimental}

Hypotonic saline solution and blood samples

Hypotonic saline solution used in the conventional OFT (batchwise method) was prepared following the recipe of $0.45 \%$ saline solution used in routine thalassemia screening at the Thalassemia Research Laboratories, Maharajnakorn Chiang Mai Hospital, Chiang Mai University, Thailand. Here, $2.812 \mathrm{~g}$ of $\mathrm{NaCl}$ (Carlo Erba), $1.424 \mathrm{~g}$ of $\mathrm{Na}_{2} \mathrm{HPO}_{4} \cdot 2 \mathrm{H}_{2} \mathrm{O}(\mathrm{BDH}), 0.262 \mathrm{~g}$ of $\mathrm{NaH}_{2} \mathrm{PO}_{4} \cdot 2 \mathrm{H}_{2} \mathrm{O}$ (Merck) and $16.744 \mathrm{~g}$ of glycerol (Carlo Erba) were dissolved in $1000 \mathrm{ml}$ of deionized (DI) water. ${ }^{10}$ The ionic strength of this hypotonic solution was calculated to be 0.074 and its $\mathrm{pH}$ was measured by a $\mathrm{pH}$ meter and was found to be 7.5.

Preparation of phosphate buffer solutions for $\mathrm{pH}$ and ionic strength studies include those with $\mathrm{pH} 7.7$ and 7.4. Phosphate buffer solution, of $\mathrm{pH} 7.7$ and $10 \mathrm{mM}$, was prepared by dissolving $1.424 \mathrm{~g}$ of $\mathrm{Na}_{2} \mathrm{HPO}_{4} \cdot 2 \mathrm{H}_{2} \mathrm{O}$ and $0.262 \mathrm{~g}$ of $\mathrm{NaH}_{2} \mathrm{PO}_{4} \cdot 2 \mathrm{H}_{2} \mathrm{O}$ in 1000 $\mathrm{ml}$ DI water. Phosphate buffer solution, of $\mathrm{pH} 7.4$ and $5 \mathrm{mM}$, was obtained by dissolving $0.658 \mathrm{~g}$ of $\mathrm{Na}_{2} \mathrm{HPO}_{4} \cdot 2 \mathrm{H}_{2} \mathrm{O}$ and 0.262 $\mathrm{g}$ of $\mathrm{NaH}_{2} \mathrm{PO}_{4} \cdot 2 \mathrm{H}_{2} \mathrm{O}$ in $1000 \mathrm{ml}$ DI water. They were degassed prior to use. Various $\mathrm{pH}$ values and ionic strengths were obtained by suitable dilution of phosphate salt and addition of $\mathrm{NaCl}$.

An isotonic solution has been reported to contain $0.9 \%(\mathrm{w} / \mathrm{v})$ $\mathrm{NaCl} .{ }^{20}$ Red blood cells will not rupture in this isotonic solution. Therefore, this solution was used as diluent for blood samples to prevent red cells from rupturing during the sample introduction waiting period of the flow system, before mixing with the hypotonic saline solution. This isotonic solution was prepared by dissolving $0.425 \mathrm{~g}$ of $\mathrm{NaCl}$ in $50 \mathrm{ml}$ of DI water.

A total of 73 blood samples were collected in Vacutainer ${ }^{\circledR}$ tubes containing EDTA as an anticoagulant (Vacutainer ${ }^{\circledR} \mathrm{K}_{2}$ EDTA tube size $3.0 \mathrm{ml}$, Becton Dickinson, USA). Blood samples can be kept for 3 days. Each blood sample was diluted 100-fold with isotonic solution before being injected into the FI system. The ability of the system to analyze a low concentration of blood should simplify the blood collection process. Drawing a very small amount or even a droplet of blood from each patient should be sufficient.

\section{Conventional OFT}

In the conventional batch-wise OFT, the procedures and

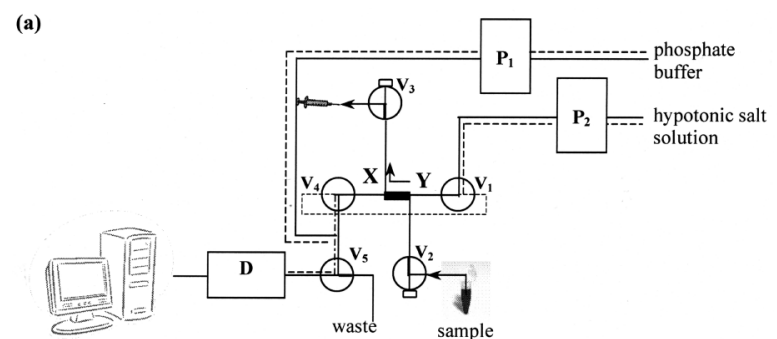

(b)
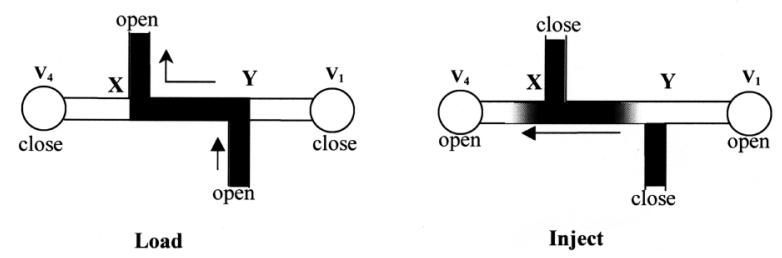

Fig. 1 (a) The stopped-flow hydrodynamic injection (SF-HI) system for Thalassemia screening: $P_{1}$ and $P_{2}$, peristaltic pumps; $V_{1}, V_{2}, V_{3}, V_{4}$, $\mathrm{V}_{5}$, three-way solenoid valves; $\mathrm{D}$, a spectronic 21 spectrophotometer coupled with a flow-through cell; from $\mathrm{X}$ to $\mathrm{Y}$, the sample zone. Dashed lines represent the flow direction of solutions during sample loading mode. (b) Illustration of flow direction using a HI system.

hypotonic saline solution used in routine screening of betathalassemia at the Maharajnakorn Chiang Mai Hospital, Chiang Mai University, Thailand were followed. A $20-\mu$ l portion of whole blood containing EDTA as an anticoagulant was added to $2 \mathrm{ml}$ of hypotonic saline solution in a test tube. The test tube was then sealed with parafilm and the solutions were mixed thoroughly. The change in turbidity was observed visually by an experienced clinical technician in $30 \mathrm{~min}$ or by a spectrophotometer as optical density (OD) at $620 \mathrm{~nm}$ within $2 \mathrm{~min}$ (from 15 to $120 \mathrm{~s}$ after mixing). In the latter case, percent hemolysis was calculated as $\left(\left(\mathrm{OD}_{15 \mathrm{~s}}-\mathrm{OD}_{120 \mathrm{~s}}\right) / \mathrm{OD}_{15 \mathrm{~s}}\right) \times 100$ and the hemolysis percent over $60 \%$ is considered as negative (normal) result. This cut-off number has been established as the result of routine screening and analysis at the Thalassemia Laboratory at Maharajnakorn Chiang Mai Hospital. ${ }^{10}$

\section{Stopped flow-hydrodynamic injection (SF-HI) system and} operational steps

The manifold of the SF-HI system used in this study is shown in Fig. 1(a). Five three-way solenoid valves (Cole-Parmer, USA) were connected as a simple electronic control injection valve based on the hydrodynamic injection principle. ${ }^{21,22}$ A lab-built programmable controller for timing control on actuation of the valves employing a microcontroller (BASIC Stamp, Parallax, Inc., USA) were used to control the direction of solution flow. A script program of Basic Stamp editor was written to switch the logic of the microcontroller port, which led to switching of the valve via a ULN2003 integrated circuit. Two peristaltic pumps (FIA Lab, USA) were used for pumping $10 \mathrm{mM}$ phosphate buffer $\mathrm{pH} 7.5$ without $\mathrm{NaCl}(\mathrm{P} 1)$ and with $0.55 \% \mathrm{NaCl}(\mathrm{P} 2)$ which act as a washing/equilibrating buffer and a hypotonic saline solution, respectively. All pump tubings were Tygon tubings (Upchurch, USA). The rest of the flow lines were assembled from fluorinated ethylene propylene (FEP) tubings (Upchurch). Each sample was introduced into the hypotonic saline solution stream by means of a hydrodynamic injection illustrated in Fig. 1(b). The approximate sample injection volume determined by calculation of tubing dimension was $40 \mu \mathrm{l}$. The mixtures of red cells and hypotonic salt solution were mixed while passing into the flow-through cell 
of $1 \mathrm{~cm}$ path length and $80 \mu \mathrm{l}$ internal volume (HELLMA, Germany), which was placed in a Spectronic 21 (Spectronic Instrument, USA). The mixture was stopped in the flow cell for $30 \mathrm{~s}$. The change in transmittance during the stopped time was observed at $620 \mathrm{~nm}$. The signal of transmittance was recorded as voltage with the lab-built computer software and BASIC Stamp data acquisition system. The slopes of signal profiles were calculated using Microsoft Excel (Microsoft, Corp., USA).

\section{Results and Discussion}

Preliminary studies for the working conditions of the SF-HI system

The purpose of this study is to develop instrumentation based on stopped flow system with $\mathrm{HI}$ in order to have automation that can differentiate negative (normal) samples from positive (carrier/disease) samples. Various parameters were optimized. These include traveling time (the time duration which each sample zone takes to move from the point of injection to the flow cell), stopped time (the time duration during which each sample zone is stopped in the flow cell), washing time (the time which each sample zone takes to completely move out of the flow cell), $\mathrm{pH}$ and ionic strength of hypotonic saline solution. Some parameters were optimized in batch-wise method because it is important to know the effects of certain parameters before setting up a suitable flow-based system.

The suitable wavelength was sought by comparing the difference of absorbance between a pooled negative sample and a pooled positive sample by batch-wise method. Each blood sample was mixed with hypotonic saline solution. The change in absorbance was monitored by the UV-VIS spectrophotometer (Lambda 25 , Perkin Elmer) in the range of $400-750 \mathrm{~nm}$ at 20,60 and $120 \mathrm{~s}$ after mixing. It was found that the differences in absorbances (due to the change in turbidity) between negative and positive samples increased with time. After $60 \mathrm{~s}$, the differences were at approximately the same magnitude over the wavelength range of $450-750 \mathrm{~nm}$. However, $620 \mathrm{~nm}$ was chosen as a detection wavelength for the direct comparison of the SF-HI system with conventional procedures where this wavelength was used in the routine analysis at the hospital.

The detailed operational steps of the system in Fig. 1(a) are as follows; the hypotonic saline solution and phosphate equilibrating buffer were propelled through the flow-through cell to adjust the baseline with the flow rate of $3.6 \mathrm{ml} / \mathrm{min}$. The carrier stream (hypotonic saline solution) was stopped by switching $\mathrm{V}_{1}$ and $\mathrm{V}_{4}$ to the sample loading mode. During the sample loading, the flow directions of each solution are represented using dashed lines. Then each blood sample was introduced into the system manually by syringe aspiration via $\mathrm{V}_{2}$ and $\mathrm{V}_{3}$. After that, flow was resumed by switching $V_{1}$ and $V_{4}$ to the injection mode, causing the sample zone $(\mathrm{X}-\mathrm{Y})$ to flow into the detector (solid line). The blood sample zone was stopped for a fixed period of time in the flowthrough cell. The change of transmittance at $620 \mathrm{~nm}$ was automatically recorded. The phosphate buffer without $\mathrm{NaCl}(\mathrm{P} 1)$, which we call the equilibrating buffer, helps to reduce the fluctuation of pressure in the flow line when switching solenoid valves that may cause unwanted sudden change of signal. This modification makes it easier to determine the slope of the signal.

The hydrodynamic injection system was employed, as shown in Fig. 1(b) and in the detailed operation previously described. The sample zone that stops in the detector is related to zone $\mathrm{X}-\mathrm{Y}$ $(\sim 40 \mu \mathrm{l})$. Introduction of a required volume of sample by the sequential injection technique can be controlled by a suitable flow direction, flow sequence and introduction of excess volume of sample. Each sample injection consumes approximately 100 $\mu \mathrm{l}$, of which $40 \mu \mathrm{l}$ is introduced into the detector. Even though this sample volume is higher than that used in batch-wise method, the ability of the SF-HI system to analyze low concentration blood sample (100-fold dilution) requires only $1 \mu \mathrm{l}$ undiluted sample as compared to $20 \mu \mathrm{l}$ undiluted sample needed for batchwise method. In addition, the possibility of cells blocking the solenoid valve should be insignificant as compared to using a sixport injection valve that has a more complex design and very narrow channels.

The traveling time, stopped time and washing time depend on the flow rate of the carrier stream. In this study, the traveling time could be evaluated from the FI-gram where the sample solution flows through the detector without stopping. The stopped time was studied by monitoring the rupture rate of the red blood cells at the selected optimum wavelength until the rate was constant. The suitable stopped time was chosen to save operation time as much as possible while the change of slope could still be clearly observed. The washing time was chosen based on the time that was needed for the base line to resume.

The $\mathrm{pH}$ and the ionic strength of hypotonic saline solution are the main parameters that affect the rupture rate of red blood cells. When one uses the proposed SF-HI system, the hypotonic saline solution with the composition as used in the reported conventional batch-wise kinetic OFT ${ }^{10}$ can not differentiate negative samples from positive samples due to the differences in sample preparation and mixing process of the on-line system as compared to batchwise method. It is necessary to investigate the operational $\mathrm{pH}$ and ionic strength for the flow system. For simplicity, the studies on the effects of $\mathrm{pH}$ and ionic strength on rupture rate of red cells were studied using the batch-wise method. Then the results obtained were adapted to be used in the flow system by taking into account the flow characteristics such as dilution and flow rate.

To study the effects of both $\mathrm{pH}$ and ionic strength at the same time, we varied the concentrations of phosphate salts in the phosphate buffers while keeping the concentrations of $\mathrm{NaCl}$ and glycerol constant. Based on the report by the Thalassemia Research Laboratory at Maharajnakorn Chiang Mai Hospital, ${ }^{10}$ $\mathrm{NaCl}$ and glycerol concentrations are kept at 48 and $182 \mathrm{mM}$, respectively. Again for simplicity, the stock of $100 \mathrm{mM} \mathrm{NaH}_{2} \mathrm{PO}_{4}$ was mixed with fixing $\mathrm{Na}_{2} \mathrm{HPO}_{4}$ concentration at $8 \mathrm{mM}$ to yield various $\mathrm{pHs}$ of 7.1, 7.5 and 7.8 and various ionic strengths of $0.05,0.06$ and 0.07 . The pHs of hypotonic solutions were measured with a $\mathrm{pH}$ meter and the ionic strengths were obtained from calculations. The range of ionic strength was chosen based on the corresponding calculated value from previously reported successful works, i.e. $0.36-0.45 \%$ hypotonic saline solution. ${ }^{8-10,15}$ The $\mathrm{pH}$ range was chosen to avoid cell deformation, explained as follows. Blood samples were mixed with buffer solutions of various pHs and ionic strengths in the ratio of $20 \mu \mathrm{l}: 2 \mathrm{ml}$ (volume blood:volume buffer). After all components were mixed, all mixtures had final $\mathrm{pHs}$ in the range of $7.2-7.5$ which are close to the $\mathrm{pH}$ value of blood in vivo $(\mathrm{pH} \sim 7.4){ }^{23}$ The $\mathrm{pH}$ of hypotonic salt solution should be controlled to be approximately in this range to prevent the deformation of cell geometry that can affect the rupture rate.

From the batch-wise optical method, a typical signal profile obtained is shown in Fig. 2. A comparison of signal slopes (calculated from the points of 17 to $27 \mathrm{~s}$ after starting the detection which was done after $15 \mathrm{~s}$ of manual mixing) of negative and positive samples at various $\mathrm{pHs}$ and ionic strengths is shown in Fig. 3. It can be concluded that both $\mathrm{pH}$ and ionic strength are important parameters for OFT as both affect the change in slope or rate of cell rupturing. However, the ionic strength is the more 


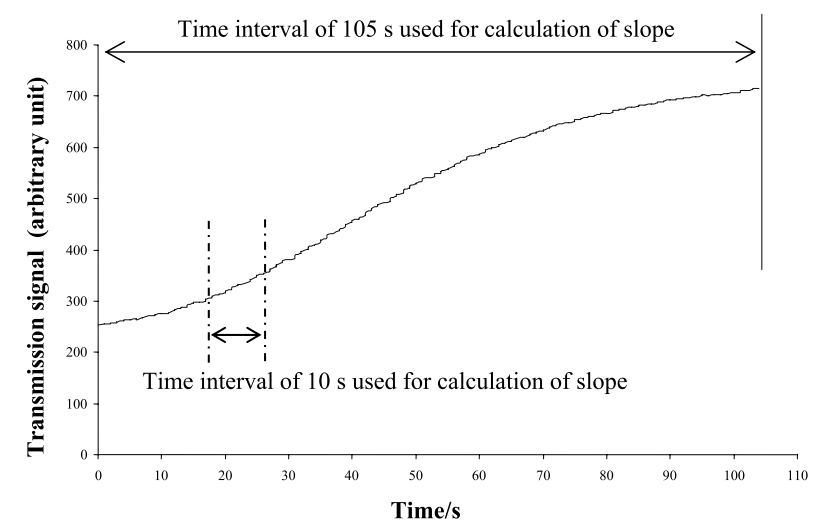

Fig. 2 Signal profile showing the change of slope due to decreasing of turbidity over time when red blood cells are placed in the hypotonic solution.

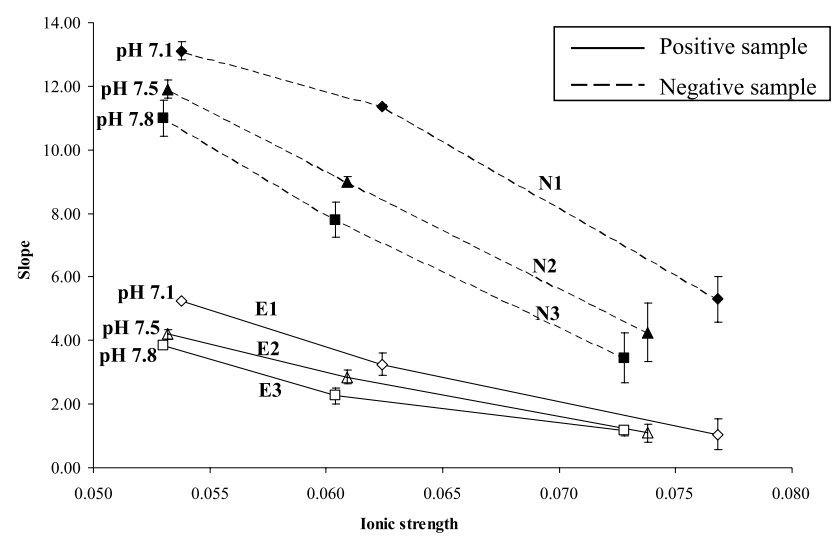

Fig. 3 The difference of slope between negative (normal designated as N1, N2 and N3 lines) and positive (disease designated as E1, E2 and E3 lines) samples in various pHs and ionic strengths.

important parameter. This is according to observation in that the slopes at various $\mathrm{pHs}$ of approximately the same ionic strength are not much different, for both the positive and negative sample groups (compare data points of approximately the same ionic strength among lines N1, N2, N3 and among lines E1, E2, E3), while the decrease in slopes is clearly observed in higher magnitude with the increase in ionic strength of hypotonic solution (compare each data point on the same line).

The differences in slopes due to negative and positive samples were clearly observed in the solution within the range of ionic strengths $0.05-0.07$. The slopes decreased with the increase in ionic strength of hypotonic solution. At high ionic strength (high amount of salt and less water), the osmosis of water into cells occurs at a lesser degree than when the ionic strength is low (low amount of salt and more water). Thus, the rupture rate of red cells in the high ionic strength solution is slower than that in the low ionic strength solution. At higher ionic strength i.e. 0.1, no slope could be observed in both negative and positive samples. This is probably due to the minute osmotic pressure of the high salt concentration solution that cannot cause cells to break in the normal time period. At too low ionic strength, red blood cells tend to break too early, which may cause difficulty in differentiation of positive from negative samples. Ionic strength may also be varied by changing the concentration of $\mathrm{NaCl}$ instead of that of the phosphate buffer. The same trend was found: the ionic strength in the range of $0.05-0.07$ was the most suitable to differentiate negative and positive samples.

The slopes of signals with various pHs were not dramatically different; however, a slight increase in slopes could be observed with the decrease in $\mathrm{pH}$ of the hypotonic saline solution. This implies that cells break slightly faster in solutions of lower $\mathrm{pHs}$ than in those of higher $\mathrm{pHs}$. The effect of $\mathrm{pH}$ on rupture rate of the red cells could be explained based on the physiology of the cell membrane. The red cell membrane has a phospholipid bilayer with protein and carbohydrate inserted in between. The $\mathrm{pH}$ affects membrane properties by changing the protein and lipid conformation and consequently by changing membrane rigidity. ${ }^{24}$

The conditions that yield the greatest difference in slopes between negative and positive samples should be chosen. Taking into account that dilution occurring in the flow system will lower the ionic strength and alter $\mathrm{pH}$ of the solution, we prepared buffer solutions at higher ionic strength and $\mathrm{pH}$ than the value needed. From the manifold in Fig. 1(a), it was assumed that hypotonic solution P2, which was merged with the equilibrating buffer P1, would be diluted 2 times when entering the flow cell. Therefore, the hypotonic solution should be prepared at twice the ionic strength needed, which should be about 0.1. This value was chosen with the expectation of having final ionic strength between $0.07-0.06$ in the flow system. The final ionic strength may not be exactly 2 times less than the original because the merging buffer $\mathrm{P} 1$ also contains phosphate salt. In terms of $\mathrm{pH}$, the hypotonic solution with final $\mathrm{pH}$ of $7.1-7.8$ yielded approximately the same degree of differences in signal between positive and negative cases at any ionic strength (compare line N1 with E1, $\mathrm{N} 2$ with E2 , and N3 with E3). Therefore, the final $\mathrm{pH}$ of 7.5 was chosen because it is the closest to the $\mathrm{pH}$ of blood and should help to prevent the deformability of cell geometry.

In practice, it is more convenient to prepare a hypotonic solution by fixing the concentration and $\mathrm{pH}$ of the phosphate buffer and by changing the concentration of added $\mathrm{NaCl}$. Based on calculation, using the flow cell volume and assuming equal flow rate $\mathrm{P} 1$ and $\mathrm{P} 2$, we estimated that $\mathrm{NaCl}$ of $95 \mathrm{mM}$ should be added into $10 \mathrm{mM}$ phosphate buffer of $\mathrm{pH} 7.7$ with ionic strength of 0.1 to yield the hypotonic $\mathrm{P} 2$ solution with $\mathrm{pH}$ of 7.5 and ionic strength of $0.07-0.05$ after dilution in the flow line. Therefore, the recipe of hypotonic saline solution used in the stopped-flow injection system was modified to contain approximately two times the amount of $\mathrm{NaCl}$ that was used in the recipe used for batch-wise test by dissolving $1.375 \mathrm{~g} \mathrm{NaCl}$ and $4.186 \mathrm{~g}$ glycerol in $250 \mathrm{ml}$ of $10 \mathrm{mM} \mathrm{pH} 7.7$ phosphate buffer solution.

Apart from ionic strength and $\mathrm{pH}$ of the hypotonic solution, other operational parameters are also to be considered. A summarization of the selected operational conditions is shown in Table 1.

\section{Analytical signal profile of negative and positive samples}

Each blood sample was mixed with the hypotonic saline solution and stopped in the flow-through cell. The rupture rate of red blood cells was monitored from the turbidity of the solution by observing the change in signal due to light transmission. Examples of signal profiles of negative and positive samples obtained from the proposed SF-HI system are illustrated in Fig. 4. Normal red cells were ruptured faster than abnormal red cells. Therefore, the slope of the analytical signal from the negative sample is higher than that of the positive sample.

The time interval for calculation of slopes is chosen based on the best discriminating signal between positive and negative samples that offered the shortest overall analysis time. It was 
Table 1 The selected operational conditions of the SF-HI system for automatic osmotic fragility test

\begin{tabular}{ll}
\hline \multicolumn{1}{c}{ Parameter } & \multicolumn{1}{c}{ Condition } \\
\hline Wavelength & $620 \mathrm{~nm}$ \\
Traveling time & $6 \mathrm{~s}$ \\
Stopped time & $30 \mathrm{~s}$ \\
Washing time & $10 \mathrm{~s}$ \\
Flow rate $\mathrm{P}_{1}, \mathrm{P}_{2}$ & $1.9 \mathrm{ml} / \mathrm{min}$ \\
(total flow rate) & $(3.6 \mathrm{ml} / \mathrm{min})$ \\
Hypotonic salt & $10 \mathrm{mM}$ phosphate buffer $\mathrm{pH} 7.7$ with $95 \mathrm{mM}$ \\
solution $\left(\mathrm{P}_{2}\right)$ & $\mathrm{NaCl}$ and $182 \mathrm{mM}$ glycerol (corresponds to \\
& ionic strength of 0.1 and final pH of 7.5$)$ \\
Equilibrating & $10 \mathrm{mM}$ phosphate buffer pH 7.5 with $182 \mathrm{mM}$ \\
solution $\left(\mathrm{P}_{1}\right)$ & glycerol \\
Interval of time & $10 \mathrm{~s}(10 \mathrm{~s}$ after the sample has entered the flow \\
for calculation & cell) \\
of slope & \\
Blood sample & $\sim 40 \mu 1$ sample zone of 100 fold dilution with \\
volume & $0.85 \%$ NaCl (approximately $100 \mu$ for total \\
& injected volume)
\end{tabular}

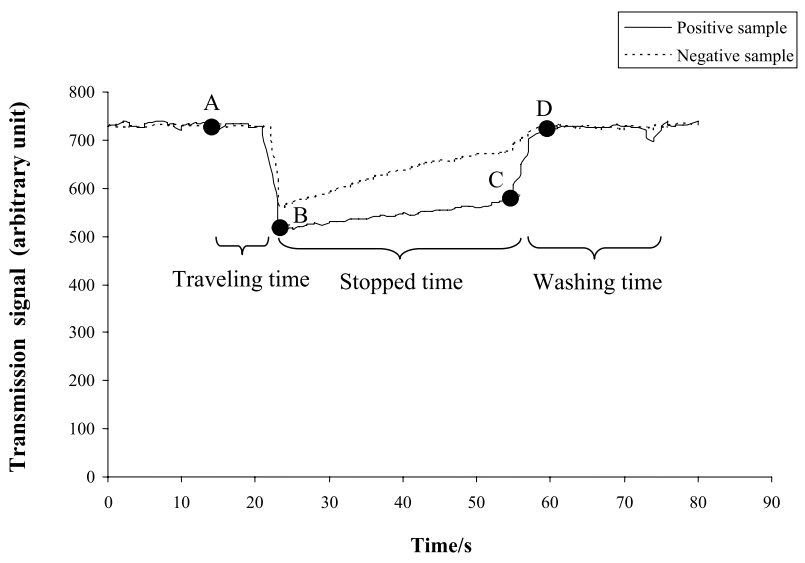

Fig. 4 Analytical signal profiles of a beta-thalassemia (positive) and a normal (negative) blood sample. A, Time at injection; B, time when sample zone is in the flow cell; A-B, traveling time; $\mathrm{C}$, time when sample zone starts moving out of the flow cell; B-C, stopped time where sample zone is left in the flow cell; $\mathrm{D}$, time when sample zone is completely moved out of the flow cell; C-D, washing time or time needed to remove all sample zone out of the flow cell.

found that the time interval of $10 \mathrm{~s}$ right after the sample zone had reached the flow cell (approximately $6 \mathrm{~s}$ after mixing, which is the same as the traveling time) is the most suitable in terms of specificity and rapidity of the analysis.

\section{Evaluation of the SF-HI system for osmotic fragility test of human} red cells

The developed flow based system was tested with 73 blood samples. The samples were independently screened by the Thalassemia Laboratory, Maharajnakorn Chiang Mai Hospital, Chiang Mai University, using a routine batch-wise kinetic OFT with optical detection with $60 \%$ hemolysis cut off level and were identified as 21 positives and 52 negatives. Although the batchwise kinetic OFT with $60 \%$ hemolysis is itself a screening technique, its performance has been studied against gold standard techniques such as $\mathrm{HbA} 2$ and PCR and satisfactory sensitivity and specificity were reported. ${ }^{10}$ Results from the positive and

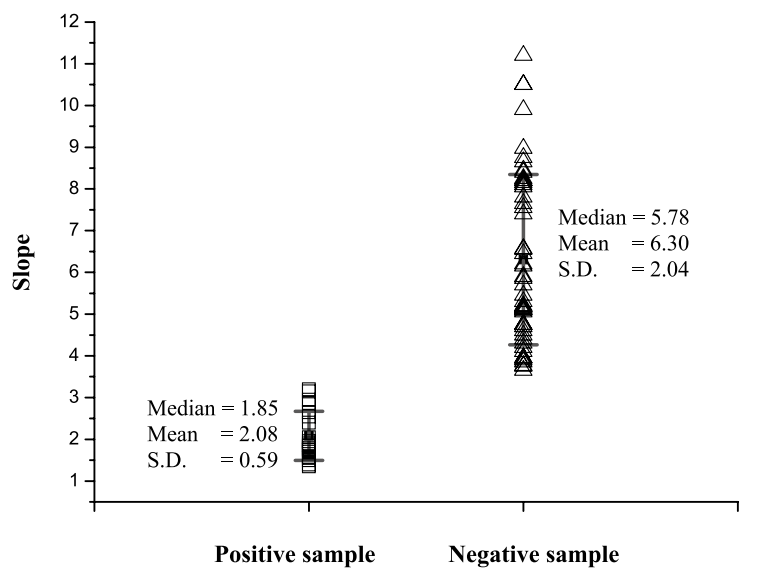

Fig. 5 Distribution of slope in positive and negative samples from the proposed SF-HI system: $\square$, positive samples; $\triangle$, negative samples.

negative groups obtained from the stopped-flow based technique and from batch-wise kinetic OFT technique were compared to evaluate the significant difference between them based on $t$-test.

The slopes of the two sample groups obtained from the proposed SF-HI system are shown in Fig. 5. The averages of slopes of positive and negative groups are significantly different $(p \leq 0.01)$. The results from this preliminary evaluation of the system demonstrated the potential system of more automatic OFT which should be rapid and reduce human errors. Additional advantages of the proposed system over the conventional batch-wise kinetic OFT include shorter analysis time (less than 1 min vs. 2 min), lower blood consumption per run ( $1 \mu \mathrm{l}$ (100 fold dilution to make $100 \mu$ l) vs. $20 \mu \mathrm{l}$ undiluted sample), and greater safety because of less possibility that the operator will have direct contact with blood samples. However, further study with a higher number of samples would be needed for determination of the exact cut off value to discriminate the two groups. Intensive statistical evaluations such as those conducted by Mamtani et al. ${ }^{25}$ compared to other gold standard techniques such as $\mathrm{HbA} 2$ quantification should be further studied.

\section{Conclusion}

A stopped flow system with hydrodynamic injection for an automatic osmotic fragility test was developed. The application for screening of beta-thalassemia trait demonstrated the benefit of the system, as compared to the conventional batch-wise operation, in terms of automation, operational safety, short analysis time, and lower blood sample consumption per run $(1 \mu \mathrm{l} v s .20 \mu \mathrm{l})$. Further work in progress utilizes a larger number of samples and data categorization through chemometrics to more effectively separate the positive and negative groups. This proposed system is composed of a simple circuit to control the solenoid valves for automatic injection with a spectrophotometer that can be changed to a laboratory-made one and a non-expensive regular option computer. The cost of the system is higher than naked eyes OFT, but with the large number of samples that need to be screened and the lack of trained personnel to judge for positive or negative results, the rapidity and precision of the system would pay for itself in the long run and/or in a situation with a number of samples to be screened with a limited budget. 


\section{Acknowledgements}

This research was supported by grant under the program Strategic Scholarships for Frontier Research Network for the Ph.D. Program Thai Doctoral degree (to S. Khonyoung) and the Research Group (RG) grant from the Commission on Higher Education (CHE), Thailand. Additional supports from the Center for Innovation in Chemistry (PERCH-CIC) and the Thailand Research Fund (TRF) are also acknowledged.

\section{References}

1. Medline Plus, Medical Encyclopedia, Osmotic Fragility, http://www.nlm.nih.gov/medlineplus/ency/article/003641.htm.

2. H. A. Massaldi, G. V. Richieri, and H. C. Mel, Biophys. J., 1998, 54, 301.

3. M. L. G. Bautista, W. Altaf, R. Lall, and R. A. Wapnir, Early Hum. Dev., 2003, 72, 37.

4. H. S. Jacob and S. Lowry, J. Clin. Invest., 1967, 46, 2083.

5. V. Suri, P. Sidhu, and K. S. B. Chopra, Indian J. Hematol. Blood Transfus., 2001, 19, 6.

6. I. Karai, K. Fukumoto, and S. Horiguchi, Int. Arch. Occup. Environ. Health, 1981, 48, 273.

7. M. S. Pitombeira, F. V. Barreto Gomes, and J. M. Martins, Mar. Biol., 1971, 9, 250.

8. M. Manglani, M. R. Lokeshwar, V. G. Vani, N. Bhatia, and V. Mhaskar, Indian Pediatr., 1997, 34, 702.

9. J. Chow, L. Phelan, and B. J. Bain, Am. J. Hematol., 2005, 79, 198

10. S. Sirichotiyakul, C. Tantipalakorn, T. Sanguansermsri, C. Wanapirak, and T. Tongsong, Int. J. Gynecol. Obstet., 2004, 86, 347.
11. T. Sanguansermsri, N. Phumyu, S. Chomchuen, and H. F. Steger, Community Genetics, 1999, 2, 26.

12. S. Panyasai, P. Sringam, G. Fucharoen, K. Sanchaisuriya, and S. Fucharoen, Acta Haematol., 2002, 108, 74.

13. K. Sanchaisuriya, S. Fucharoen, G. Foochareon, T. Ratanasiri, P. Sanchaisuriya, Y. Changtrakul, U. kosanakarn, W. Ussawaphark, and F. P. Schelp, Am. J. Clin. Pathol., 2005, 123, 113.

14. A. El-Beshlaway, N. Kaddah, A. Moustafa, G. Mouktar, and I. Youssry, East. Mediterr. Health J., 2007, 13, 780.

15. C. Kattamis, G. Efremov, and S. Pootrakul, J. Med. Genet., 1981, 18, 266.

16. K. Grudpan, P. Ampan, Y. Udnan, S. Jayasvati, S. Lapanantnoppakhun, J. Jakmunee, G. D. Christian, and J. Ruzicka, Talanta, 2002, 58, 1319.

17. H. Ronghuan, J. Hua, and W. Jinhua, Mikrochim. Acta, 2003, $141,93$.

18. K. Grudpan, Talanta, 2004, 64, 1084.

19. O. Tue-Ngeun, J. Jakmunee, and K. Grudpan, Talanta, 2005, $68,459$.

20. J. K. Hardy, Osmosis, http://www.biologie.uni-hamburg.de/ b-online/e22/22c.htm.

21. J. Růžička and E. H. Hansen, "Flow Injection Analysis", 2nd ed., 1988, John Wiley and Sons, New York.

22. S. Somnam, J. Jakmunee, and K. Grudpan, Spectrosc. Lett., 2008, 41, 221.

23. R. Casiday and R. Frey, "Blood, Sweat and Buffers: $p H$ Regulation During Exercise", http://www.chemistry.wustl. edu/ edudev/LabTutorials/Buffer/Buffer.html.

24. SparkNotes: Today's most popular study guide from Barnes \& Noble, The cell membrane, http://www.sparknotes.com/ testprep/books/sat2/biology/chapter4section4.rhtml.

25. M. Mamtani, A. Jawahirani, K. Das, V. Rughwani, and H. Kalkarni, Hematology, 2006, 11, 277. 